\title{
Proceedings of the 10th Workshop on Implementation, Compilation, Optimization of Object-Oriented Languages, Programs and Systems (ICOOOLPS'15)
}

\author{
2015, Prague, Czech Republic
}

\author{
Program Comittee : \\ Floréal Morandat (Chair) - Enseirb-Matmeca \\ Carl Friedrich Bolz - King's College London \\ Eric Jul - Alcatel-Lucent Bell Labs \\ Tobias Pape - Hasso-Plattner-Institute, Potsdam \\ Jean Privat - Université du Québec à Montréal \\ Jeremy Singer - University of Glasgow \\ Gaël Thomas - Telecom SudParis \\ Laurence Tratt - King's College London \\ Jan Vitek - Northeastern University \\ Mario Wolczko - Oracle Labs \\ Olivier Zendra (Co-chair) - INRIA / LORIA
}




\section{The Association for Computing Machinery \\ 2 Penn Plaza, Suite 701 \\ New York New York 10121-0701}

ACM COPYRIGHT NOTICE. Copyright 2015 by the Association for Computing Machinery, Inc. Permission to make digital or hard copies of part or all of this work for personal or classroom use is granted without fee provided that copies are not made or distributed for profit or commercial advantage and that copies bear this notice and the full citation on the first page. Copyrights for components of this work owned by others than ACM must be honored. Abstracting with credit is permitted. To copy otherwise, to republish, to post on servers, or to redistribute to lists, requires prior specific permission and/or a fee. Request permissions from Publications Dept., ACM, Inc., fax +1 (212) 869-0481, or permissions@acm.org.

For other copying of articles that carry a code at the bottom of the first or last page, copying is permitted provided that the per-copy fee indicated in the code is paid through the Copyright Clearance Center, 222 Rosewood Drive, Danvers, MA 01923, +1-978-750-8400, +1-978-750-4470 (fax).

Notice to Past Authors of ACM-Published Articles

ACM intends to create a complete electronic archive of all articles and/or other material previously published by ACM. If you have written a work that was previously published by ACM in any journal or conference proceedings prior to 1978, or any SIG Newsletter at any time, and you do NOT want this work to appear in the ACM Digital Library, please inform permissions@acm.org, stating the title of the work, the author(s), and where and when published.

ACM ISBN: 978-1-4503-3657-4/15/07 
ICOOOLPS'15 TABLE OF CONTENTS

Data-centric Metaprogramming in Object-Oriented Languages Vlad Ureche (abstract)

Building Debuggers and Other Tools: We Can "Have it All" Michael L. Van De Vanter

Trace-based Debugging for Advanced-Dispatching Programming Languages

Christoph Bockisch, Marnix van't Riet, Haihan Yin, Mehmet Aksit, Ziyi Lin, Yuting Chen, Jianjun Zhao

Preexistence revisited

Roland Ducournau, Julien Pagès, Jean Privat, Colin Vidal (abstract)

Call-target-specific Method Arguments

Fabio Niephaus, Matthias Springer, Tim Felgentreff, Tobias Pape, Robert Hirschfeld

Metis: A Smart Memory Allocator Using Historical Reclamation Information

Shijie Xu, Qi Guo, Gerhard Dueck, David Bremner, Yang Wang

Towards Reducing the Need for Algorithmic Primitives in Dynamic Language VMs Through a Tracing JIT

Tim Felgentreff, Tobias Pape, Lars Wassermann, Robert Hirschfeld, Carl Friedrich Bolz

Techniques and Applications for Guest-Language Safepoints Benoit Daloze, Chris Seaton, Daniele Bonetta, Hanspeter Mössenböck 